\title{
A Comprehensive Assessment of the Racial and Ethnic Disparities in the Incidence of Gastric Cancer in the United States, 1992-2014
}

\author{
Oiang Yao, $\mathrm{MD}, \mathrm{PhD} \mathrm{D}^{1,2}$ \\ Xiaona Qi, MMed ${ }^{3}$ \\ Wen Cheng, MD, $\mathrm{PhD}{ }^{1}$ \\ Shao-Hua Xie, MD, $\mathrm{PhD}^{4}$
}

${ }^{1}$ Department of Ultrasound Intervention, Harbin Medical University Cancer Hospital, Harbin, ${ }^{2}$ Heilongjiang Provincial Academy of Medical Sciences, Harbin,

${ }^{3}$ Nursing Department, Harbin Medical

University Cancer Hospital, Harbin, China,

${ }^{4}$ Upper Gastrointestinal Surgery,

Department of Molecular Medicine and

Surgery, Karolinska Institutet, Karolinska

University Hospital, Stockholm, Sweden
Correspondence: Wen Cheng, MD, PhD Department of Ultrasound Intervention, Harbin Medical University Cancer Hospital, Harbin 150081, Heilongjiang Province, China Tel: $86-17088338733$

Fax: 86-45186298125

E-mail: ambercountry@foxmail.com

Received March 7, 2018

Accepted June 18, 2018

Published Online June 19, 2018

\section{Purpose}

This study aimed to evaluate the racial and ethnic disparities in the incidence of gastric cancer and their temporal trends in the United States.

\section{Materials and Methods}

Using data from 13 cancer registries in the Surveillance, Epidemiology, and End Results database, we assessed such disparities during 1992-2014 in the United States using a variety of disparity metrics.

\section{Results}

The age-standardized incidence rate of non-cardia gastric cancer was highest in Asian and Pacific Islanders, while the incidence of cardia gastric was highest in non-Hispanic whites in men and was similarly low in all groups in women. The incidence of non-cardia gastric cancer decreased in all groups over time, particularly in Asian and Pacific Islanders (on average by $3 \%$ per year). The incidence of cardia gastric remained relatively stable in virtually all racial/ethnic groups. The racial and ethnic disparities in gastric cancer incidence steadily decreased over time as measured on the absolute scale, which was mainly driven by the reduced disparities in non-cardia gastric cancer. The range difference in the incidence of gastric cancer decreased on average by $4.1 \%$ per year in men and by $2.6 \%$ per year in women from 1992 to 2014 . The between group variance decreased by $5.6 \%$ per year in men and by $3.4 \%$ per year in women. The relative-scale disparity measures generally remained stable over time.

\section{Conclusion}

This study demonstrates decreased racial and ethnic disparities in the incidence of gastric cancer over time in the United States, particularly as measured on the absolute scale.

\section{Introduction}

Gastric cancer is the fifth commonest type of malignancy worldwide with an estimated nearly one million new cases occurring globally each year [1]. Gastric cancer varies greatly in epidemiology and risk factors across anatomic subsites [2-4]. Non-cardia gastric cancer accounts for the majority of all gastric cancer cases. Helicobacter pylori infection is a major risk factor for non-cardia gastric cancer, but it does not
Key words

Stomach neoplasms, Race/ethnicity, Disparity, Incidence 
was higher in whites, particularly in men [5-7]. However, the temporal trends in the incidence of gastric cancer across racial and ethnic groups have not been updated recently. Moreover, health disparity is a complex conception and is heavily related to the specific disparity indicators used when measuring such disparity. However, the racial and ethnic disparities in gastric cancer have not been measured thoroughly.

Using data from the Surveillance, Epidemiology, and End Results (SEER) Program, we aimed to characterize the racial and ethnic disparities in the incidence of gastric cancer by anatomic subsite, i.e., cardia and non-cardia gastric cancers, in the United States during a period of over 20 years. Multiple disparity measures were used for evaluating different aspects of such disparity.

\section{Materials and Methods}

\section{Data sources}

We extract data on incident cases of gastric cancer (topography code $\mathrm{C} 16$ according to the International Classification of Diseases for Oncology, 3rd edition [ICD-O-3]) and population data during the period 1992-2014 from the SEER database in the United States, using the SEER ${ }^{*}$ Stat ver. 8.3.4 [8]. Data were extracted from the November 2016 submission of the SEER 13 registries database, which included data from the 13 cancer registries in the United States, namely Atlanta, Connecticut, Detroit, Hawaii, Iowa, New Mexico, San Francisco-Oakland, Seattle-Puget Sound, Utah, Los Angeles, San Jose-Monterey, Rural Georgia, and the Alaska Native Tumor Registry. The SEER 13 registries database has contained expanded data according to categories of race and ethnicity since the year 1992. The SEER 13 registries database covers approximately $13.4 \%$ of the total population in the United States.

\section{Statistical analysis}

We categorized all participants into the following five racial/ethnic groups: non-Hispanic whites, Hispanic whites, blacks, Asian and Pacific Islanders, and other specified. We calculated the annual age-standardized incidence rates by sex and racial/ethnic group using the United States Standard Population in 2000 as the reference. We estimated the average annual percentage change (AAPC) and the corresponding $95 \%$ confidence interval $(\mathrm{CI})$ in the age-standardized incidence rate using log-linear regressions, under the assumption that the rate changed at a constant percentage ever year during the study period.

We measured the racial/ethnic disparities in the incidence of gastric cancer using the following six health disparity indicators which measure different aspects of the disparity: range difference $(\mathrm{RD})$, between group variance (BGV), range ratio (RR), index of disparity (IDisp), mean log deviation (MLD), and Theil index (T). Among these indicators, RD and BGV measure the absolute difference in the incidence between social groups, while the remaining four are measures on the relative scale. RD, RR, and IDisp do not account for population sizes of different racial/ethnic groups, while the other three measures are weighted by the population size of each group. The detailed characteristics of these disparity measures can be found in the supplementary material (S1 Table) and elsewhere [9-11]. We calculated these disparity measures by sex and calendar year and percentage change since 1992 in these measures for each calendar year. We performed Joinpoint regression identify any changing points of the temporal trends in these disparity measures and to estimate the annual percent change in each segment of time period. The AAPC was also computed as a summary measure of the trend over the whole study period.

The age-standardized incidence rates were calculated for total gastric cancer, and for cardia gastric cancer (ICD-O-3 code C16.0) and non-cardia gastric cancer (ICD-O-3 codes C16.1-C16.6) separately. The disparity measures were calculated for total gastric cancer and non-cardia gastric cancer separately, but not for cardia gastric cancer due to small number of cases of cardia gastric cancer stratified by racial/ ethnic group. All statistical analyses were performed using the Joinpoint Regression Program ver. 4.4.0.0 and Health Disparities Calculator (HD*Calc) ver. 1.2.4, both of which were developed by the National Institute of Cancer of the United States [11,12].

\section{Results}

\section{Incidence trends by racial/ethnic group}

This study included a total of 72,748 patients with newly diagnosed gastric cancer, identified from the SEER 13 registries during 1992-2014, among which 43,975 (60\%) were males and 28,773 (40\%) were females. Table 1 presents the age-standardized incidence rates of gastric cancer by sex and anatomic subsite for each racial/ethnic group and the AAPCs in the rates during the study period. The sex-specific annual incidence rates in the four major racial/ethnic groups are plotted in Fig. 1.

In 1992, the age-standardized incidence rate of total gastric 
Table 1. Age-standardized incidence rate (1/100,000 person-years) of gastric cancers by sex and race/ ethnicity group in the United States, 1992-2014

\begin{tabular}{|c|c|c|c|c|c|c|c|c|}
\hline & \multicolumn{2}{|c|}{$1992-2014$} & \multicolumn{2}{|c|}{1992} & \multicolumn{2}{|c|}{2014} & \multirow{2}{*}{ AAPC } & \multirow{2}{*}{$95 \% \mathrm{CI}$} \\
\hline & No. & Rate & No. & Rate & No. & Rate & & \\
\hline \multicolumn{9}{|l|}{ Total gastric cancer } \\
\hline \multicolumn{9}{|l|}{ Males } \\
\hline Non-Hispanic white & 24,242 & 9.3 & 1,118 & 11.6 & 1,042 & 7.8 & -1.8 & -2.0 to -1.7 \\
\hline Hispanic white & 6,316 & 16.7 & 201 & 20.2 & 362 & 13.5 & -2.0 & -2.4 to -1.5 \\
\hline Black & 5,062 & 17.2 & 209 & 20.8 & 218 & 12.4 & -2.2 & -2.7 to -1.7 \\
\hline Asian/Pacific Islander & 7,678 & 19.0 & 287 & 28.0 & 396 & 14.6 & -3.0 & -3.3 to -2.7 \\
\hline Other specified & 513 & 13.5 & 13 & 11.4 & 28 & 10.6 & -0.9 & -2.6 to 0.9 \\
\hline Total & 43,975 & 11.8 & 1,831 & 14.3 & 2,067 & 10.0 & -1.7 & -1.8 to -1.6 \\
\hline \multicolumn{9}{|l|}{ Females } \\
\hline Non-Hispanic white & 13,928 & 4.1 & 684 & 5.0 & 514 & 3.2 & -1.4 & -1.8 to -1.1 \\
\hline Hispanic white & 4,967 & 10.0 & 155 & 11.7 & 299 & 9.1 & -0.9 & -1.3 to -0.3 \\
\hline Black & 3,768 & 8.9 & 130 & 9.2 & 173 & 7.0 & -1.2 & -1.9 to -0.6 \\
\hline Asian/Pacific Islander & 5,645 & 10.7 & 185 & 14.7 & 248 & 6.9 & -2.9 & -3.4 to -2.4 \\
\hline Other specified & 348 & 7.2 & 9 & 8.0 & 26 & 7.9 & -0.3 & -2.2 to 1.6 \\
\hline Total & 28,773 & 5.9 & 1,164 & 6.6 & 1,278 & 5.0 & -0.8 & -1.0 to -0.6 \\
\hline \multicolumn{9}{|l|}{ Gastric cardia cancer } \\
\hline \multicolumn{9}{|l|}{ Males } \\
\hline Non-Hispanic white & 11,464 & 4.3 & 463 & 4.6 & 603 & 4.4 & -0.3 & -0.6 to 0.0 \\
\hline Hispanic white & 1,122 & 2.9 & 50 & 4.4 & 80 & 3.0 & -1.5 & -2.7 to -0.4 \\
\hline Black & 723 & 2.4 & 21 & 2.0 & 33 & 1.8 & -0.3 & -1.5 to 1.0 \\
\hline Asian/Pacific Islander & 1,148 & 2.8 & 32 & 2.8 & 75 & 2.7 & -0.8 & -1.5 to -0.1 \\
\hline Other specified & 116 & 3.2 & 5 & 3.2 & 6 & 2.1 & - & - \\
\hline Total & 14,614 & 3.8 & 572 & 4.2 & 802 & 3.8 & -0.7 & -0.9 to -0.4 \\
\hline \multicolumn{9}{|l|}{ Females } \\
\hline Non-Hispanic white & 3,047 & 0.9 & 124 & 0.9 & 138 & 0.8 & 0.5 & -0.2 to 1.2 \\
\hline Hispanic white & 491 & 1.0 & 17 & 1.2 & 29 & 0.9 & -0.7 & -2.4 to 0.9 \\
\hline Black & 351 & 0.8 & 7 & 0.5 & 21 & 0.8 & 0.7 & -1.7 to 3.1 \\
\hline Asian/Pacific Islander & 433 & 0.8 & 15 & 1.2 & 26 & 0.7 & -1.6 & -3.3 to 0.1 \\
\hline Other specified & 50 & 1.1 & 1 & 1.1 & 5 & 1.4 & - & - \\
\hline Total & 4,384 & 0.9 & 164 & 0.9 & 219 & 0.8 & -0.2 & -0.3 to 0.7 \\
\hline \multicolumn{9}{|l|}{ Non-cardia gastric cancer } \\
\hline \multicolumn{9}{|l|}{ Males } \\
\hline Non-Hispanic white & 9,044 & 3.6 & 448 & 4.8 & 331 & 2.6 & -3.1 & -3.3 to -2.9 \\
\hline Hispanic white & 3,743 & 10.0 & 119 & 11.8 & 196 & 7.4 & -2.3 & -2.9 to -1.6 \\
\hline Black & 3,034 & 10.4 & 126 & 12.5 & 145 & 8.3 & -2.4 & -3.0 to -1.8 \\
\hline Asian/Pacific Islander & 4,968 & 12.4 & 192 & 18.6 & 231 & 8.7 & -3.3 & -3.8 to -2.8 \\
\hline Other specified & 264 & 7.0 & 6 & 6.7 & 14 & 5.5 & -1.1 & -3.8 to 1.6 \\
\hline Total & 21,134 & 5.8 & 892 & 7.1 & 925 & 4.5 & -2.2 & -2.4 to -2.0 \\
\hline \multicolumn{9}{|l|}{ Females } \\
\hline Non-Hispanic white & 7,657 & 2.2 & 383 & 2.8 & 278 & 1.8 & -1.9 & -2.3 to -1.5 \\
\hline Hispanic white & 3,179 & 6.5 & 108 & 8.3 & 178 & 5.4 & -1.2 & -1.8 to -0.6 \\
\hline Black & 2,326 & 5.5 & 83 & 6.0 & 91 & 3.7 & -1.1 & -1.8 to -0.3 \\
\hline Asian/Pacific Islander & 3,962 & 7.5 & 134 & 10.4 & 178 & 5.1 & -2.9 & -3.3 to -2.4 \\
\hline Other specified & 205 & 4.4 & 5 & 3.8 & 14 & 4.4 & -1.8 & -4.4 to 1.0 \\
\hline Total & 17,403 & 3.6 & 714 & 4.0 & 752 & 3.0 & -1.0 & -1.2 to -0.7 \\
\hline
\end{tabular}

AAPC, average annual percent change; $\mathrm{CI}$, confidence interval. 
A
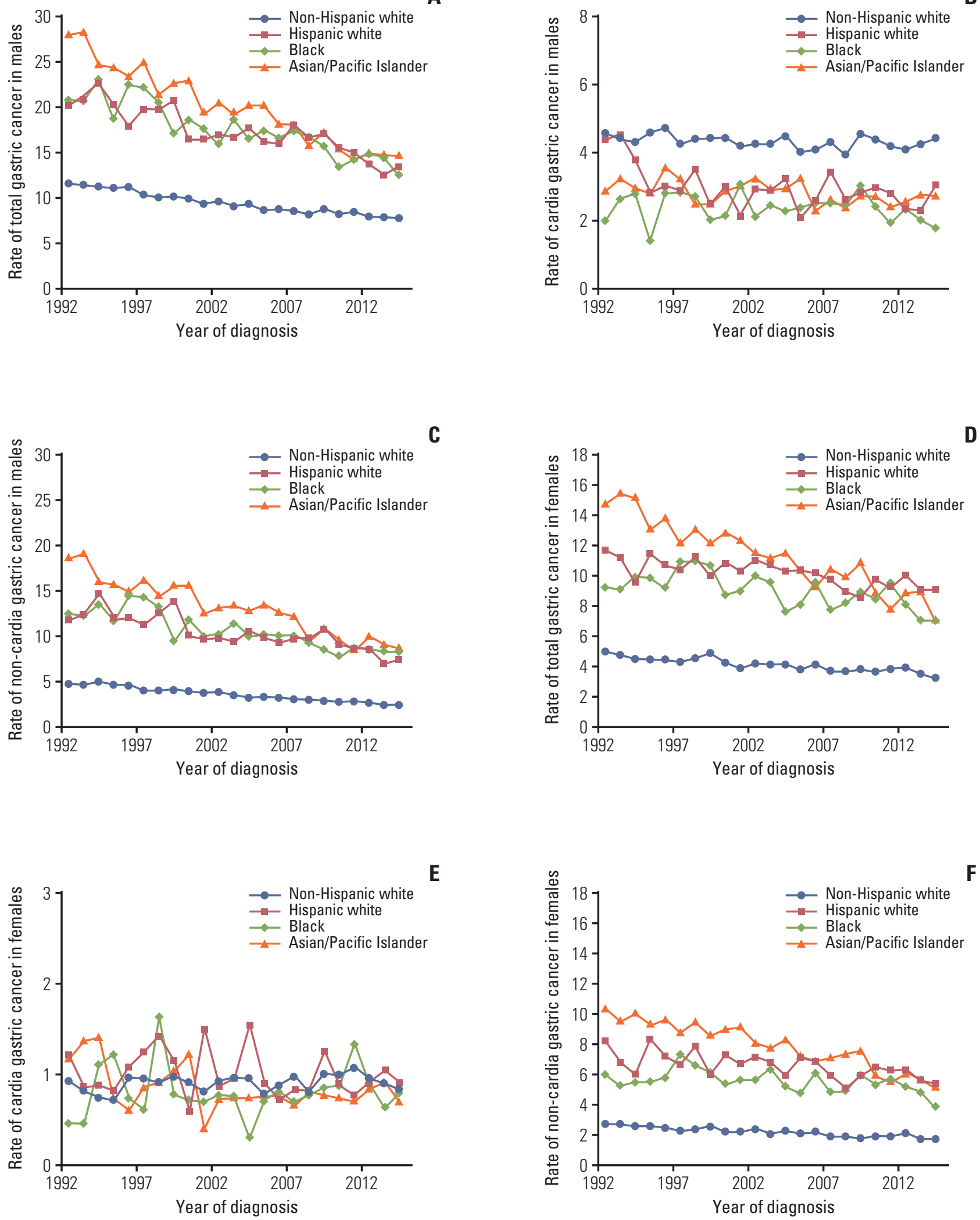

Fig. 1. Sex-specific age-standardized incidence rates of gastric cancer by anatomic subsite and racial/ethnic group in the Surveillance, Epidemiology, and End Results 13 registries in the United States during 1992-2014. 
Table 2. Changes in racial and ethnic disparities in the incidence of total gastric cancer and non-cardia gastric cancer by sex in the United States, 1992-2014

\begin{tabular}{|c|c|c|c|c|c|}
\hline & \multicolumn{2}{|c|}{1992} & \multicolumn{2}{|c|}{2013} & \multirow{2}{*}{$\begin{array}{c}\% \text { Change, } \\
1992-2013\end{array}$} \\
\hline & Index & $95 \% \mathrm{CI}$ & Index & $95 \% \mathrm{CI}$ & \\
\hline \multicolumn{6}{|l|}{ Total gastric cancer } \\
\hline \multicolumn{6}{|l|}{ Males } \\
\hline \multicolumn{6}{|l|}{ Absolute scale } \\
\hline Range difference & 16.6 & 9.1 to 24.2 & 6.8 & 5.3 to 8.4 & -58.9 \\
\hline Between-group variance & 40.0 & 20.4 to 41.6 & 8.5 & 5.4 to 11.5 & -72.7 \\
\hline \multicolumn{6}{|l|}{ Relative scale } \\
\hline Range ratio & 2.5 & 1.3 to 4.5 & 1.9 & 1.7 to 2.1 & -23.8 \\
\hline Index of disparity & 77.4 & -29.3 to 184.0 & 64.1 & 44.8 to 83.5 & -17.1 \\
\hline Mean log deviation & 0.06 & 0.04 to 0.07 & 0.04 & 0.03 to 0.05 & -31.9 \\
\hline Theil index & 0.06 & 0.04 to 0.08 & 0.04 & 0.03 to 0.05 & -36.2 \\
\hline \multicolumn{6}{|l|}{ Female } \\
\hline \multicolumn{6}{|l|}{ Absolute scale } \\
\hline Range difference & 9.7 & 7.5 to 11.9 & 5.9 & 4.8 to 7.0 & -39.6 \\
\hline Between-group variance & 11.8 & 7.7 to 16.0 & 6.0 & 4.1 to 7.8 & -49.6 \\
\hline \multicolumn{6}{|l|}{ Relative scale } \\
\hline Range ratio & 2.9 & 2.5 to 3.5 & 2.8 & 2.4 to 3.3 & -4.2 \\
\hline Index of disparity & 118.3 & 82.4 to 154.2 & 140.1 & 104.4 to 175.7 & 18.4 \\
\hline Mean log deviation & 0.09 & 0.07 to 0.12 & 0.10 & 0.08 to 0.13 & 9.5 \\
\hline Theil index & 0.10 & 0.07 to 0.12 & 0.10 & 0.07 to 0.12 & 0.1 \\
\hline \multicolumn{6}{|l|}{ Non-cardia gastric cancer } \\
\hline \multicolumn{6}{|l|}{ Male } \\
\hline \multicolumn{6}{|l|}{ Absolute scale } \\
\hline Range difference & 13.7 & 10.9 to 16.6 & 6.1 & 4.9 to 7.3 & -55.6 \\
\hline Between-group variance & 21.3 & 14.4 to 28.2 & 7.4 & 5.4 to 9.4 & -65.2 \\
\hline \multicolumn{6}{|l|}{ Relative scale } \\
\hline Range ratio & 3.8 & 3.2 to 4.6 & 3.4 & 2.9 to 4.0 & -11.7 \\
\hline Index of disparity & 156.8 & 111.9 to 201.7 & 193.5 & 144.7 to 242.4 & 23.4 \\
\hline Mean log deviation & 0.14 & 0.10 to 0.18 & 0.16 & 0.12 to 0.19 & 11.6 \\
\hline Theil index & 0.15 & 0.11 to 0.18 & 0.14 & 0.11 to 0.17 & -1.7 \\
\hline \multicolumn{6}{|l|}{ Female } \\
\hline \multicolumn{6}{|l|}{ Absolute scale } \\
\hline Range difference & 7.6 & 5.8 to 9.5 & 3.7 & 2.8 to 4.5 & -51.6 \\
\hline Between-group variance & 7.5 & 4.7 to 10.3 & 2.6 & 1.7 to 3.6 & -64.6 \\
\hline \multicolumn{6}{|l|}{ Relative scale } \\
\hline Range ratio & 3.8 & 3.1 to 4.6 & 3.1 & 2.6 to 3.8 & -17.2 \\
\hline Index of disparity & 156.1 & 108.9 to 203.4 & 166.1 & 114.7 to 217.6 & 6.4 \\
\hline Mean log deviation & 0.15 & 0.11 to 0.19 & 0.13 & 0.09 to 0.17 & -10.5 \\
\hline Theil index & 0.15 & 0.11 to 0.19 & 0.12 & 0.09 to 0.16 & -19.1 \\
\hline
\end{tabular}

CI, confidence interval.

cancer was the highest in Asian and Pacific Islanders, followed by blacks and Hispanic whites, and the lowest in nonHispanic whites, in both sexes. The rate decreased steadily in all racial/ethnic groups, regardless of sex, from 1992 to 2014. The decrease was steeper in Asian and Pacific Islanders (on average by $3 \%$ per year in both sexes) compared with that in other groups. In 2014, the rate remained lower in nonHispanic whites and similarly higher in other groups, regardless of sex.

The incidence rate of cardia gastric cancer in men was higher in non-Hispanic whites and similarly lower in other racial/ethnic groups, while the rate in women was lower 
A

B
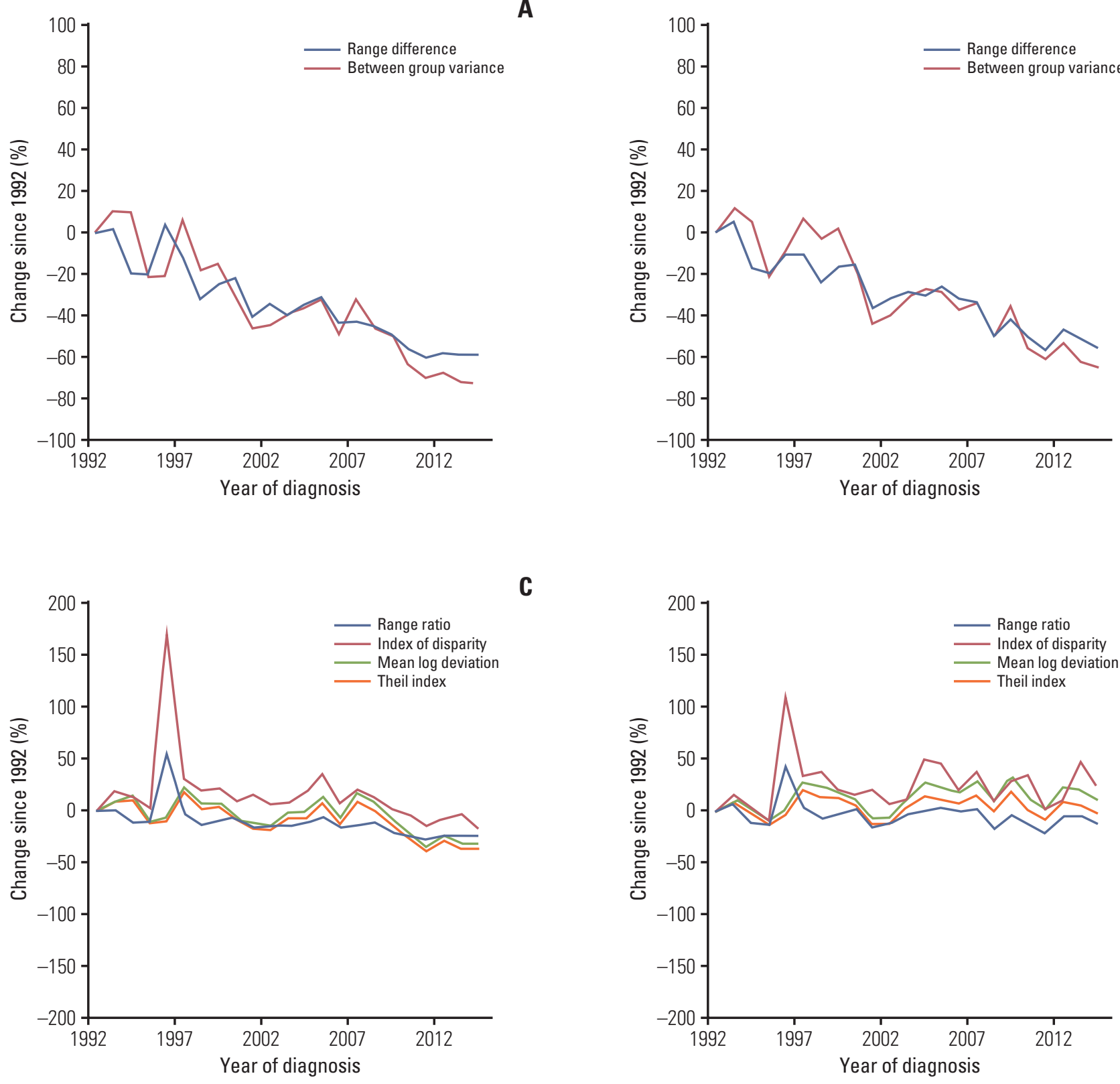

C

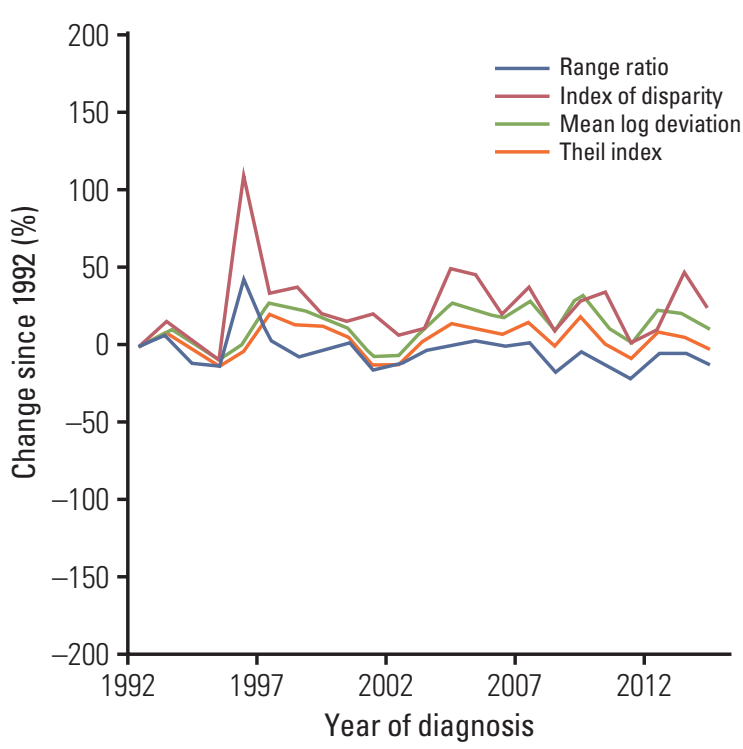

Fig. 2. Percent changes since 1992 in the racial and ethnical disparities in the incidence of total gastric cancer and non-cardia gastric cancer in men in the Surveillance, Epidemiology, and End Results 13 registries in the United States during 1992-2014. (A) Absolute measures for total gastric cancer. (B) Absolute measures for non-cardia gastric cancer. (C) Relative measures for total gastric cancer. (D) Relative measures for non-cardia gastric cancer.

than $2 / 100,000$ person-years in all groups throughout the study period. The incidence rate of cardia gastric cancer remained relatively stable over time, except for a slight decrease in Hispanic white men (AAPC, $-1.5 ; 95 \%$ CI, -2.7 to -0.4 ). The incidence rate of non-cardia gastric cancer showed similar pattern as that of total gastric cancer in both sexes.

\section{Racial and ethnic disparities in total gastric cancer}

Table 2 presents the absolute and relative measures of racial and ethnic disparity in the incidence of total gastric cancer and non-cardia gastric cancer by sex in the beginning and ending calendar years, and the percent changes in these measures during the study period. The percent changes since 


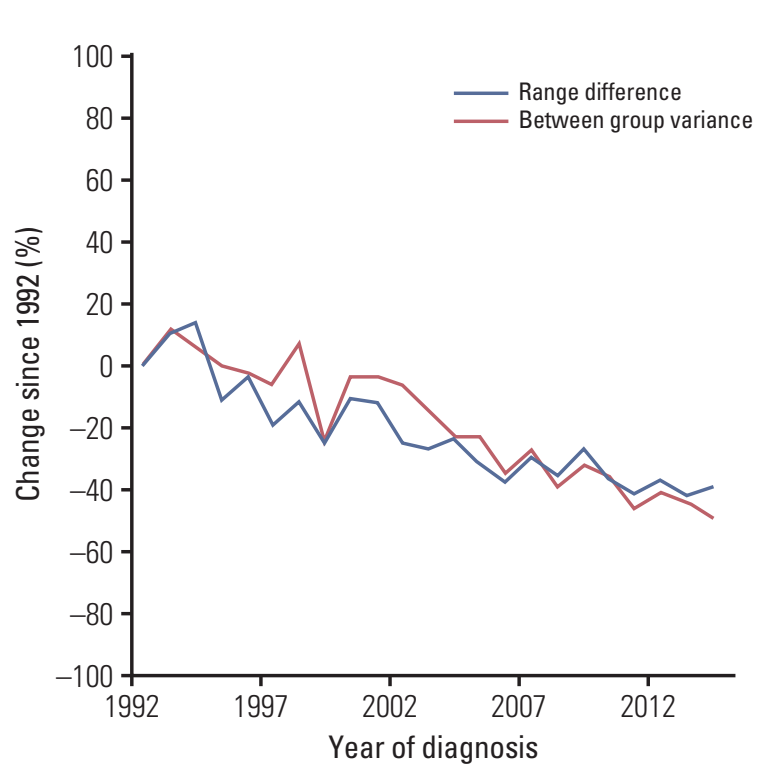

A
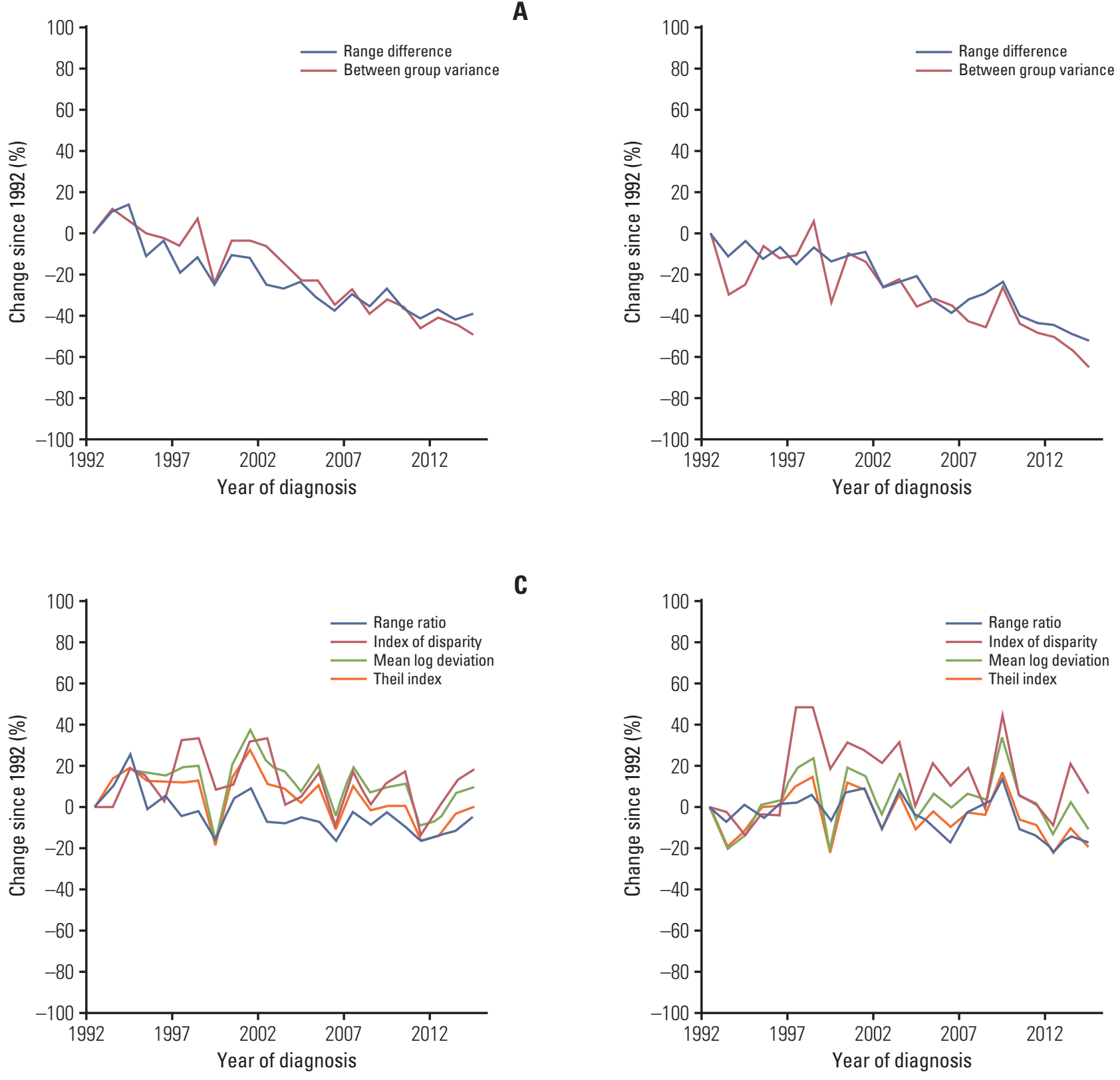

C

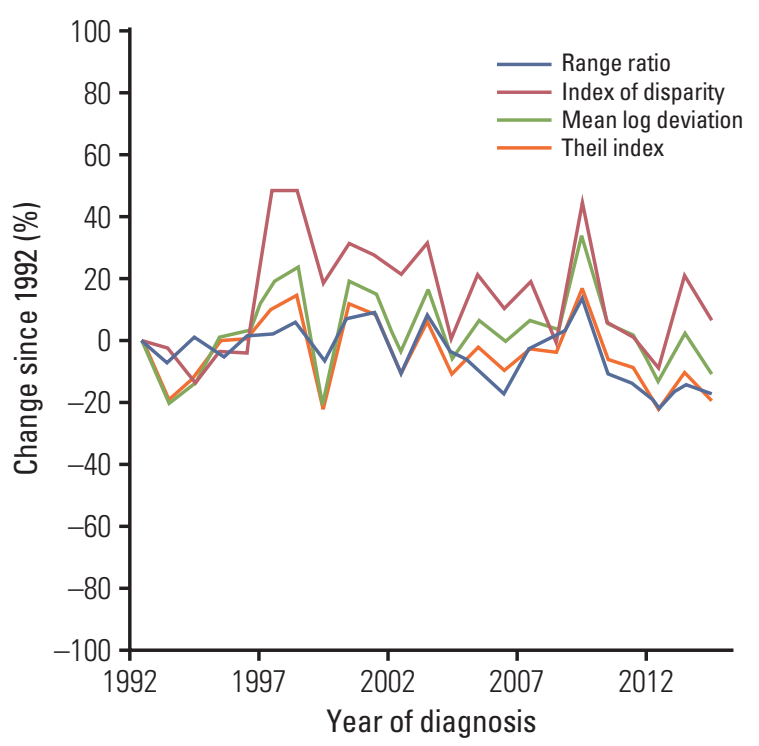

Fig. 3. Percent changes since 1992 in the racial and ethnical disparities in the incidence of total gastric cancer and non-cardia gastric cancer in men in the Surveillance, Epidemiology, and End Results 13 registries in the United States during $1992-2014$. (A) Absolute measures for total gastric cancer. (B) Absolute measures for non-cardia gastric cancer. (C) Relative measures for total gastric cancer. (D) Relative measures for non-cardia gastric cancer.

1992 in disparity measures for each calendar year in men and in women are shown in Figs. 2 and 3, respectively. Table 3 presents results from Joinpoint regression on these racial and ethnic disparity measures by sex.

The absolute disparity measures RD and BGV for the incidence of total gastric cancer decreased during the study period in both sexes (Figs. 2A and 3A). The RD for total gas- tric cancer decreased on average by $4.1 \%$ per year in men and by $2.6 \%$ per year in women from 1992 to 2014 (Table 3). The BGV for total gastric cancer decreased on average by $5.6 \%$ per year in men and by $3.4 \%$ per year in women during the observation period.

The relative disparity measures for total gastric cancer in men decreased over the entire study period, which was how- 
Table 3. Joinpoint regression on racial and ethnic disparity measures of the incidence of total gastric cancer and non-cardia gastric cancer by sex in the United States, 1992-2014

\begin{tabular}{|c|c|c|c|c|c|c|}
\hline & \multicolumn{3}{|c|}{ Total gastric cancer } & \multicolumn{3}{|c|}{ Non-cardia gastric cancer } \\
\hline & Period & APC & $95 \% \mathrm{CI}$ & Period & APC & $95 \% \mathrm{CI}$ \\
\hline \multicolumn{7}{|l|}{ Male } \\
\hline \multicolumn{7}{|l|}{ Absolute scale } \\
\hline Range difference & 1992-2014 & -4.1 & -4.7 to -3.4 & $1992-2014$ & -3.5 & -4.1 to -2.9 \\
\hline Between-group variance & 1992-2014 & -5.6 & -6.7 to -4.5 & $1992-2014$ & -4.8 & -5.8 to -3.9 \\
\hline \multicolumn{7}{|l|}{ Relative scale } \\
\hline Range ratio & $1992-2014$ & -1.9 & -2.7 to -1.1 & $1992-2014$ & -0.5 & -1.0 to 0.1 \\
\hline Index of disparity & $1992-2014$ & -1.3 & -2.1 to -0.5 & $1992-2014$ & 0.5 & -0.4 to 1.4 \\
\hline \multirow[t]{3}{*}{ Theil index } & 1992-2007 & -0.0 & -1.4 to 1.3 & 1992-2014 & 0.6 & -0.1 to 1.3 \\
\hline & 2007-2014 & -6.6 & -10.8 to -2.2 & & & \\
\hline & AAPC & -2.2 & -3.7 to -0.6 & & & \\
\hline \multirow[t]{3}{*}{ Mean log deviation } & 1992-2008 & -0.6 & -1.8 to 0.6 & 1992-2014 & 0.1 & -0.6 to 0.7 \\
\hline & 2008-2014 & -7.6 & -12.9 to -1.9 & & & \\
\hline & AAPC & -2.5 & -4.2 to -0.8 & & & \\
\hline \multicolumn{7}{|l|}{ Female } \\
\hline \multicolumn{7}{|l|}{ Absolute scale } \\
\hline \multirow[t]{3}{*}{ Range difference } & 1992-2014 & -2.6 & -3.1 to -2.1 & 1992-2009 & -2.2 & -2.9 to -1.5 \\
\hline & & & & 2009-2014 & -7.0 & -11.2 to -2.6 \\
\hline & & & & AAPC & -3.3 & -4.4 to -2.2 \\
\hline Between-group variance & 1992-2014 & -3.4 & -4.0 to -2.8 & 1992-2014 & -3.5 & -4.5 to 2.4 \\
\hline \multicolumn{7}{|l|}{ Relative scale } \\
\hline Range ratio & 1992-2014 & -0.8 & -1.3 to -0.4 & 1992-2014 & -0.6 & -1.0 to -0.1 \\
\hline \multirow[t]{3}{*}{ Index of disparity } & 1992-2014 & -0.3 & -1.1 to 0.5 & 1992-1998 & 6.9 & -0.2 to 14.4 \\
\hline & & & & $1998-2014$ & -1.4 & -2.9 to 0.1 \\
\hline & & & & AAPC & 0.8 & -1.2 to 2.8 \\
\hline Theil index & $1992-2014$ & -0.5 & -1.2 to 0.2 & 1992-2014 & 0.1 & -0.8 to 1.0 \\
\hline Mean log deviation & 1992-2014 & -0.9 & -1.6 to -0.3 & 1992-2014 & -0.5 & -1.3 to 0.3 \\
\hline
\end{tabular}

$\mathrm{APC}$, annual percent change; $\mathrm{CI}$, confidence interval; AAPC, average annual percent change.

ever slighter compared with the decrease in absolute disparity measures (Fig. 2C). The RR and IDisp for total gastric cancer in men decreased at constant rates during the study period. On the other hand, the $\mathrm{T}$ for total gastric cancer in men remained stable from 1992 to 2007 and decreased on average by $6.6 \%$ per year from 2007 to 2014 , and the decrease in MLD started from 2008 onwards, on average by 3.4\% per year (Table 3). The relative disparity measures for total gastric cancer in women remained relatively stable during the study period, except for a slight decrease in RR by $0.8 \%$ per year (Table 3, Fig. 3C).

\section{Racial and ethnic disparities in non-cardia gastric cancer}

The absolute disparity measures RD and BGV for the incidence of non-cardia gastric cancer steadily decreased over time in both sexes (Figs. 2B and 3B), which was in similar pat- terns as for total gastric cancer. The relative disparity measures for the incidence of non-cardia gastric cancer remained relatively stable during the study period in both sexes, except for a slight decrease in RR on average by $0.6 \%$ per year in women (Table 3, Fig. 3D).

\section{Discussion}

We measured the racial and ethnic disparities in the incidence of gastric cancer, based on a variety of disparity measures, during a period of over 20 years from 1992 to 2014 in the United States. The incidence rate of non-cardia gastric cancer decreased in all racial/ethnic groups, and the decrease was steeper in Asian and Pacific Islanders than in the other 
groups. On the other hand, the incidence rate of cardia gastric remained relatively stable over time in virtually all racial / ethnic groups, except for a slight decrease in Hispanic white men. We observed steadily decreased racial and ethnic disparities in the incidence of gastric cancer over time as measured on the absolute scale, which was mainly driven by the reduced disparities in the incidence of non-cardia gastric cancer. The relative-scale measures for the racial and ethnic disparities in the incidence of gastric cancer generally remained stable over the entire study period, but showed a seemingly decrease in recent years in men.

We observed substantially higher incidence of non-cardia gastric cancer in Asian and Pacific Islanders relative to other racial/ethnic groups, which is in line with previous studies $[5,6]$. The higher risk of non-cardia gastric cancer in Asian American than in other racial/ethnic groups may be partly explained by a historically higher prevalence of $H$. pylori infection [13-15]. Nevertheless, the observed racial/ethnic disparities in the incidence of non-cardia gastric cancer contradict with historic differences in the prevalence of tobacco smoking and alcohol consumption across racial/ethnic groups, i.e., a substantially lower prevalence of smoking in Asian American and higher prevalence of alcohol consumption in whites $[16,17]$. The incidence of non-cardia gastric cancer decreased over time in all racial/ethnic groups, corresponding to the declining prevalence of $H$. pylori infection and tobacco smoking in all racial/ethnic groups in the United States [16-18]. However, the magnitude of decline in the incidence of non-cardia gastric cancer and the prevalence of $H$. pylori infection and smoking might not exactly correlate with each other according to racial/ ethnic group. For example, the smoking prevalence has decreased more dramatically in Asian and Hispanic Americans than in blacks and non-Hispanic whites [16,17], while our results showed that the decrease in non-cardia gastric cancer incidence was slightly steeper in non-Hispanic whites and Asian Americans than in the other groups. Some other risk factors, including dietary factors, and interactions between risk factors might also have contributed to the observed racial and ethnic disparities in the incidence of non-cardia gastric cancer [2,3].

Cardia gastric cancer may share some risk factors with esophageal adenocarcinoma, including obesity and gastroesophageal reflux disease [19-21]. Particularly, abdominal obesity other than general obesity has been suggested to be an important risk factor for esophageal adenocarcinoma and cardia gastric cancer [22]. Smoking seems a moderate risk factor for cardia gastric cancer, while $H$. pylori infection dose not increase the risk of cardia gastric cancer [2,3]. We did not observe distinct racial and ethnic disparities in the incidence of cardia gastric cancer, except for a higher risk in white men than in men of other racial/ ethnic groups. The higher risk in white men may be explained by the higher prevalence of abdominal obesity and reflux in white men compared with other groups [23-26]. In contrast to an increasing incidence of esophageal adenocarcinoma in the United States $[9,21]$, we did not observe any increase in the incidence of cardia gastric cancer. However, any conclusion regarding the temporal trend in the incidence of cardia gastric cancer cannot be drawn considering potential misclassification of these two types of cancer.

To our knowledge, this study is the most comprehensive assessment of the racial and ethnic disparities in the incidence of gastric cancer in the American population. We used a variety of health disparity measures which take into account different aspects of measuring health disparity, including indicators on both relative and absolute scales and treating individuals and groups equally $[10,11,27]$. The absolute disparity measures provide information on the absolute gap in the disease burden across racial/ethnic groups, while the relative disparity measures may be more relevant in etiology. Our findings suggest a significant decrease in the absolute gap in the incidence of gastric cancer across racial/ethnic groups in the United States. Although these are not merely specific to gastric cancer, achieving health equity, eliminating disparities, and improving the health of all groups have been set as one of the overarching goals in Healthy People 2010 and Healthy People 2020 programs in the United States [28]. The decreased absolute racial and ethnic disparities in gastric cancer observed in this study is no doubt supporting evidence for the success of such public health strategies in the United States, and continued efforts to eliminating health disparity in the specific context of gastric cancer would be encouraged. On the other hand, the relative disparity measures had remained relatively stable over time as compared with absolute measures, indicating that substantial changes in the risk factor profiles of gastric cancer are less likely to have occurred in the American population. The disparity measures weighted by population sizes of racial/ethnic groups and those unweighted measures generally showed similar results, indicating that the results were not dominated by any racial/ethnic group of large size. Considering the complex conception of health disparity, interpretation of the results should be made taking into account all these disparity measures and the specific question to be answered in practice [11,29].

Several limitations in the present study warrant discussion. First, we only used data from the SEER13 cancer registries because expanded categories of racial/ethnic groups are available in these registries for a long period. Therefore, findings presented in this study may not be simply generalized to the total population of the United States. Second, due to the limited number of cases in each racial/ethnic group, we were unable to calculate the disparity measures by calendar year and perform Joinpoint regression for the incidence car- 
dia gastric cancer. Third, considering the limited incidence of gastric cancer of histology other than adenocarcinoma and the substantial missing in histological type, we could not perform stratified analyses by histological type. Last, because the SEER database does not contain information on risk factors, we could not direct evaluate how the observed disparities in the incidence of gastric cancer could be explained by the major risk factors in the study population.

In conclusion, this comprehensive assessment of the racial and disparity in the incidence of gastric cancer in the United States demonstrates a steady decrease in such disparities over time, particularly as measured on the absolute scale. Such decrease was mainly driven by the reduced disparities in the incidence of non-cardia gastric cancer and may be attributable to the decreasing prevalence of $H$. pylori infection in the population which was more rapid in Asian Americans.

\section{Electronic Supplementary Material}

Supplementary materials are available at Cancer Research and Treatment website (https:// www.e-crt.org).

\section{Conflicts of Interest}

Conflict of interest relevant to this article was not reported.

\section{Acknowledgments}

This work was supported by grants from Harbin City Research and Development Project on Applied Technologies (No. 2016RAQXJ152), Heilongjiang Provincial Health and Family Planning Commission Research Fund (No. 2013087) and Harbin Medical University Innovative Scientific Research Fund (No. 2016RWZX21).

\section{References}

1. Global Burden of Disease Cancer Collaboration, Fitzmaurice C, Allen C, Barber RM, Barregard L, Bhutta ZA, et al. Global, regional, and national cancer incidence, mortality, years of Life lost, years lived with disability, and disability-adjusted lifeyears for 32 cancer groups, 1990 to 2015: a systematic analysis for the global burden of disease study. JAMA Oncol. 2017;3: 524-48.

2. Karimi P, Islami F, Anandasabapathy S, Freedman ND, Kamangar F. Gastric cancer: descriptive epidemiology, risk factors, screening, and prevention. Cancer Epidemiol Biomarkers Prev. 2014;23:700-13.

3. Rugge M, Genta RM, Di Mario F, El-Omar EM, El-Serag HB, Fassan M, et al. Gastric cancer as preventable disease. Clin Gastroenterol Hepatol. 2017;15:1833-43.

4. Colquhoun A, Arnold M, Ferlay J, Goodman KJ, Forman D, Soerjomataram I. Global patterns of cardia and non-cardia gastric cancer incidence in 2012. Gut. 2015;64:1881-8.

5. Wu X, Chen VW, Ruiz B, Andrews P, Su LJ, Correa P. Incidence of esophageal and gastric carcinomas among American Asians / Pacific Islanders, whites, and blacks: subsite and histology differences. Cancer. 2006;106:683-92.

6. Wu X, Chen VW, Andrews PA, Ruiz B, Correa P. Incidence of esophageal and gastric cancers among Hispanics, non-Hispanic whites and non-Hispanic blacks in the United States: subsite and histology differences. Cancer Causes Control. 2007;18:585-93.

7. Kubo A, Corley DA. Marked multi-ethnic variation of esophageal and gastric cardia carcinomas within the United States. Am J Gastroenterol. 2004;99:582-8.

8. Surveillance Research Program, National Cancer Institute. SEER ${ }^{\star}$ Stat software, version 8.3.4 [Internet]. Bethesda, MD: National Cancer Institute; 2018 [cited 2018 Jun 2]. Available from: http://seer.cancer.gov/ seerstat.

9. Xie SH, Rabbani S, Petrick JL, Cook MB, Lagergren J. Racial and ethnic disparities in the incidence of esophageal cancer in the United States, 1992-2013. Am J Epidemiol. 2017;186:134151.

10. Harper S, Lynch J, Meersman SC, Breen N, Davis WW, Reichman ME. An overview of methods for monitoring social disparities in cancer with an example using trends in lung cancer incidence by area-socioeconomic position and race-ethnicity, 1992-2004. Am J Epidemiol. 2008;167:889-99.

11. Breen N, Scott S, Percy-Laurry A, Lewis D, Glasgow R. Health disparities calculator: a methodologically rigorous tool for analyzing inequalities in population health. Am J Public Health. 2014;104:1589-91.

12. Kim HJ, Fay MP, Feuer EJ, Midthune DN. Permutation tests for joinpoint regression with applications to cancer rates. Stat Med. 2000;19:335-51.

13. Brenner H, Arndt V, Stegmaier C, Ziegler H, Rothenbacher D. Is Helicobacter pylori infection a necessary condition for noncardia gastric cancer? Am J Epidemiol. 2004;159:252-8.

14. Huerta-Franco MR, Banderas JW, Allsworth JE. Ethnic/ racial differences in gastrointestinal symptoms and diagnosis associated with the risk of Helicobacter pylori infection in the US. Clin Exp Gastroenterol. 2018;11:39-49.

15. Taylor VM, Ko LK, Hwang JH, Sin MK, Inadomi JM. Gastric cancer in Asian American populations: a neglected health disparity. Asian Pac J Cancer Prev. 2014;15:10565-71.

16. Jamal A, Homa DM, O'Connor E, Babb SD, Caraballo RS, Singh T, et al. Current cigarette smoking among adults: United States, 2005-2014. MMWR Morb Mortal Wkly Rep. 2015;64: 1233-40.

17. Clarke TC, Ward BW, Schiller JS. Early release of selected 
estimates based on data from the January-March 2016 National Health Interview Survey. Atlanta, GA: Centers for Disease Control and Prevention; 2016.

18. Nagy P, Johansson S, Molloy-Bland M. Systematic review of time trends in the prevalence of Helicobacter pylori infection in China and the USA. Gut Pathog. 2016;8:8.

19. Lagergren J, Lagergren P. Recent developments in esophageal adenocarcinoma. CA Cancer J Clin. 2013;63:232-48.

20. Rustgi AK, El-Serag HB. Esophageal carcinoma. N Engl J Med. 2014;371:2499-509.

21. Coleman HG, Xie SH, Lagergren J. The epidemiology of esophageal adenocarcinoma. Gastroenterology. 2018;154:390405.

22. Singh S, Sharma AN, Murad MH, Buttar NS, El-Serag HB, Katzka DA, et al. Central adiposity is associated with increased risk of esophageal inflammation, metaplasia, and adenocarcinoma: a systematic review and meta-analysis. Clin Gastroenterol Hepatol. 2013;11:1399-412.e7.

23. Okosun IS, Choi ST, Boltri JM, Parish DC, Chandra KM, Dever GE, et al. Trends of abdominal adiposity in white, black, and Mexican-American adults, 1988 to 2000. Obes Res. 2003;11: 1010-7.
24. El-Serag HB, Petersen NJ, Carter J, Graham DY, Richardson P, Genta RM, et al. Gastroesophageal reflux among different racial groups in the United States. Gastroenterology. 2004;126: 1692-9.

25. Wen M, Kowaleski-Jones L, Fan JX. Ethnic-immigrant disparities in total and abdominal obesity in the US. Am J Health Behav. 2013;37:807-18.

26. Petrick JL, Nguyen T, Cook MB. Temporal trends of esophageal disorders by age in the Cerner Health Facts database. Ann Epidemiol. 2016;26:151-4.e4.

27. Harper S, Lynch J. Selected comparisons of measures of health disparities: a review using databases relevant to healthy people 2010 cancer-related objectives. NCI Cancer Surveillance Monograph Series, No. 7. NIH Pub. No. 07-6281. Bethesda, MD: National Cancer Institute; 2007.

28. Healthy People 2020 [Internet]. Washington, DC: U.S. Department of Health and Human Services, Office of Disease Prevention and Health Promotion; 2018 [cited 2018 May 1]. Available from: https://www.healthypeople.gov/2020/about/ foundation-health-measures / Disparities.

29. Kindig D. Population health equity: rate and burden, race and class. JAMA. 2017;317:467-8. 